\title{
Compact ventilation and heat pump with recirculation air for renovation of small apartments
}

\author{
Toni Calabrese ${ }^{1}$, Fabian Ochs ${ }^{1,}{ }^{*}$, Dietmar Siegele ${ }^{1}$, and Georgios Dermentzis ${ }^{1}$ \\ ${ }^{1}$ Unit for Energy Efficient Building, University of Innsbruck, Innsbruck, Austria
}

\begin{abstract}
A new compact and cost effective heating and ventilation concept for decentral renovation of small flats in multifamily houses was developed and investigated in the framework of the Austrian project "SaLüH!" through a dynamic building and HVAC simulation study based on results of laboratory measurements of functional models. The system consists of a façade integrated supply air/exhaust air heat pump equipped with a desuperheater allowing to increase the heating power and to add more freedom to control the system. The simulation results show that such a system is able to improve the thermal comfort of the flat (compared to the standard heating concept without desuperheater) with good indoor air quality and satisfying energy performance. The proposed system - because of its versatility and compactness - represents an ideal solution for decentral renovation of flats in multi-family houses, especially in case of limited space inside the flat and if central solutions are not possible for technical, economic or social reasons.
\end{abstract}

\section{Introduction and motivation}

The building sector is responsible for a large percentage of the world energy requirements. This percentage reaches the value of $40 \%$ of the total energy consumption in the European Union. Thus, a future sustainable energy system requires a deep renovation of existing buildings.

While renovation to very low energy consumption by renovating with Passive House components to e.g. the socalled EnerPHit standard is well proven, the renovation of the HVAC system represents often a major hurdle in particular in multi-family homes. Non-disruptive renovation of flats is not trivial due to a number of complications (technical, economic, social). Innovative technologies and smart renovation strategies are required (see e.g. EU fp7 project iNSPiRe).

So-called Passive House compact hat pump units for ventilation, heating (optionally cooling) and domestic hot water (DHW) preparation consisting of a mechanical ventilation with heat recovery, an exhaust air heat pump and a small DHW store are a proven cost-effective and efficient technology that exist since more than 20 years. However, in spite of their name, market available systems are far too big to be installed in small flats or apartments of typical multi-family houses.

Within the EU fp7 project iNSPiRe and followed by the Austrian FFG project SalüH! cost-effective compact ventilation and heat pump units were developed as one of the possible solutions for energy renovation of small flats, especially in case of limited space [1]. Such a system can be completely integrated in the façade and thus minimizes the space required for renovation inside the flat. In addition, electricity required by the system can be potentially covered by a photovoltaic (PV) system installed on the roof or on the façade of the flat [2]. Compactness, versatility and high potential of selfsufficiency make this system ideal for renovation of low energy demand multi-family buildings.

An improved variant of such a system was investigated within the framework of the Austrian project "SaLüH!" [3] and is described in the following sections. This new ventilation and heating concept is based on a supply air exhaust air heat pump, with higher heating power and better control options of the system ensured by the use of a second condenser (i.e. desuperheater) with recirculation of secondary air.

\section{Method}

The proposed system was developed and tested in the laboratory and then modelled in the CARNOT/Simulink simulation environment. A simulation study for a flat of a typical multi-family house (MFH) was performed in order to investigate the performances of the heating system, as well as thermal comfort and indoor air quality (IAQ) in the flat.

A comparison between this new system (i.e. with desuperheater with recirculation of secondary air) and the standard system (i.e. supply air - exhaust air HP without desuperheater) is discussed in section 5 .

\subsection{Simulation platform}

The simulation platform used is CARNOT, a toolbox extension for MATLAB/SIMULINK. University of Innsbruck developed a modified version of CARNOT

* Corresponding author: Fabian.Ochs@uibk.ac.at 
toolbox (called carnotUIBK) with which an object of the building is created in MATLAB reading the information from an Excel file. This version of the CARNOT toolbox gives the possibility to change most relevant parameters (e.g. HVAC system, controls, model of door opening, etc.) easily in MATLAB/Excel.

The moisture transport and buffering within the building envelope and the exchange of humidity between the walls and the ambient was taken into account.

The heat pump model is a dynamic model based on a look up table which is parameterized using measurement results. The ERV model was implemented, using the etaNTU $\left(\right.$ eta $\left._{\mathrm{x}}-\mathrm{NTU}_{\mathrm{x}}\right)$ analytical approach, also parameterized using measurement results, see [4].

\subsection{Reference Building}

The building under investigation is a typical multi-story building (see Fig. 1). It consists of five stories and two symmetrical flats for each storey. The basement and the staircase are not heated. The reference flat (highlighted in red in Fig. 1) considered here, is the flat on the first floor oriented to the Northeast side.
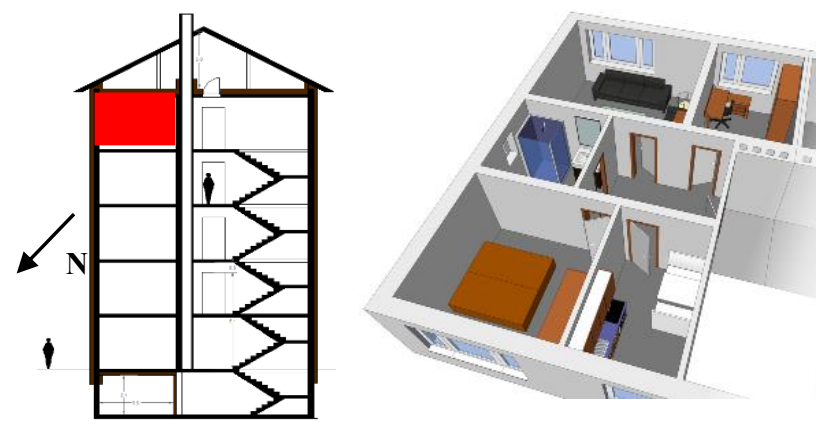

Fig. 1. Side view (left) of the multi-storey building (10 flats, two symmetrical flats for each store) and 3D view of the flat under investigation (right)

The reference flat is shown in Fig. 2. The flat has a total heated area of $70.9 \mathrm{~m}^{2}$ and it consists in six rooms: kitchen (KI), sleeping room (SL), corridor (CO), bathroom (BA), child room $(\mathrm{CH})$ and living room (LI).

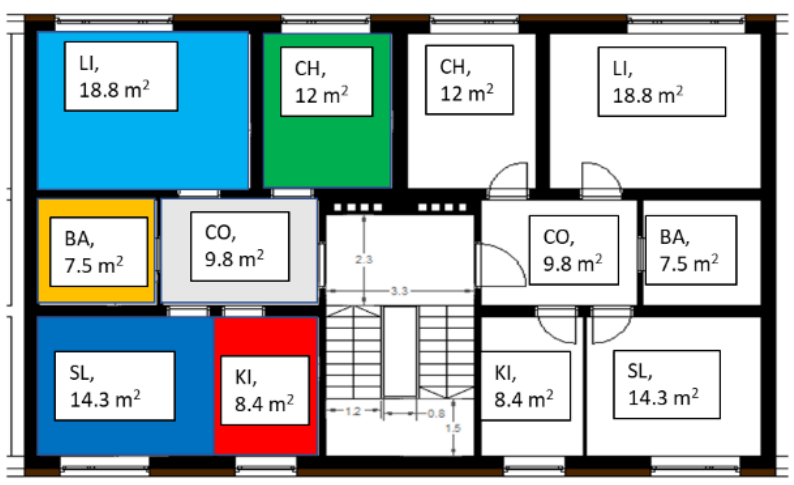

Fig. 2. 2D view of the reference flat (total area of $70.9 \mathrm{~m}^{2}$ ). Two symmetrical flats were assumed for each storey of the building

The flat is conceived to be occupied by 3 persons (ca. $23 \mathrm{~m}^{2} /$ person). The daily schedule of the occupation profile is valid also during the weekend. An air change rate of $0.07[1 / \mathrm{h}]$ due to infiltration through the façade is assumed. Opening of the windows in summer period is considered for each room. Air exchange between two adjacent zones through the opening of the doors was modelled in MATLAB/SIMULINK, based on the equations used in the tool CONTAM [5]. Additional information regarding the building model and the flat can be found in 7 .

\section{Façade integrated supply air heat HP with recirculation of secondary air combined with ERV}

\subsection{Overview}

Fig. 3 shows a $3 \mathrm{D}$ view of the flat with a possible configuration of the proposed heating and ventilation system. In this case, the system is installed similar to a conventional HP split unit with an outdoor unit (but integrated in the façade of the flat) and an indoor unit (installed in the ceiling of the kitchen), see also [1].

The supply air - exhaust air heat pump system with inverter technology is equipped in addition to the condenser which heats the supply air to max. $52{ }^{\circ} \mathrm{C}$ with a second condenser in which secondary air is heated. The secondary air is extracted from and supplied to the corridor (i.e. secondary air recirculation). The use of secondary air increases the heating power of the heat pump and gives the opportunity to split the power, allowing a better control of the heat pump system. The system uses the necessary ducts of the ventilation system to distribute space heating power plus one additional pair of ducts for the recirculation from the kitchen to the corridor. The air distribution system is placed in the corridor and supplies fresh air to the sleeping room, child room and living room. An electric radiator is placed in the bathroom for reasons of comfort.

The hydraulic scheme of the heating and ventilation system is shown in Fig. 4. The fresh air is heated by a preheater, an energy recovery ventilation (ERV) unit, the condenser of the heat pump and, additionally, a postheater if the power of heat pump is insufficient, before it is supplied and distributed to the flat. The air is extracted from bathroom and kitchen, cooled in the ERV unit and its energy is used as source for the heat pump. The evaporator of the heat pump is placed in the exhaust airflow after the energy recovery ventilation and uses the remaining enthalpy of the exhaust air. Additional ambient air can be used as source of the heat pump. The secondary air, extracted from the corridor of the flat, is heated in the desuperheater (i.e. "DESUP" in Fig. 4) and is supplied to the corridor.

One of the big advantages of such a system is the possibility to distribute heating power to the flat using the ventilation ducts. A simplified scheme of the decentralized ventilation system (without the heat pump for a better comprehension) is reported in Fig. 5. A mass balanced ERV unit supplies fresh air to the sleeping room (SL), child room $(\mathrm{CH})$ and living room (LI) and extracts air from the kitchen (KI) and bathroom (BA). 


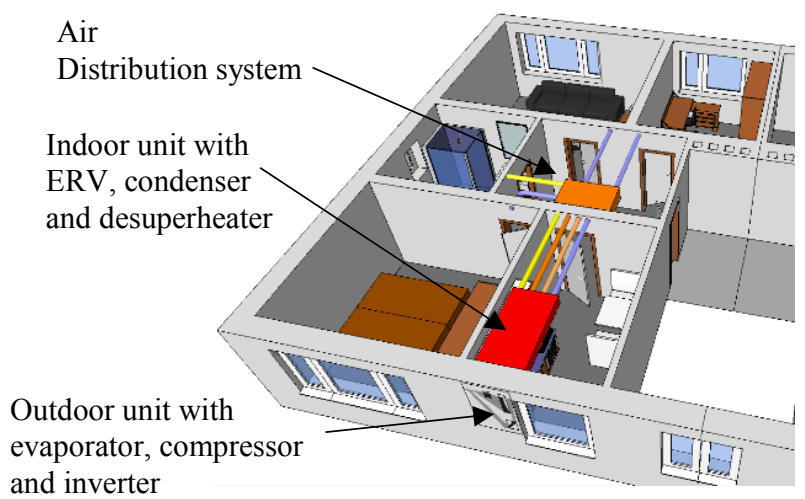

Fig. 3. 3D view of the flat with the supply and secondary air heat pump system. The outdoor unit is integrated in the façade, while the indoor unit is installed on the ceiling of the kitchen. An air distribution system is installed in the corridor to supply air to the SL, LI and CH and collects air from the BA

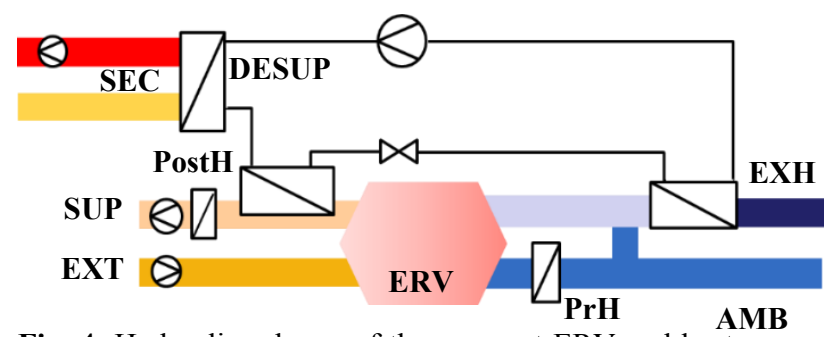

Fig. 4. Hydraulic scheme of the compact ERV and heat pump system with recirculation air. "PostH" and "PrH" represent the post-heater and the pre-heater, respectively. "DESUP" indicates the second condenser (i.e. desuperheater) of the heat pump that is used to heat the recirculation air in the corridor

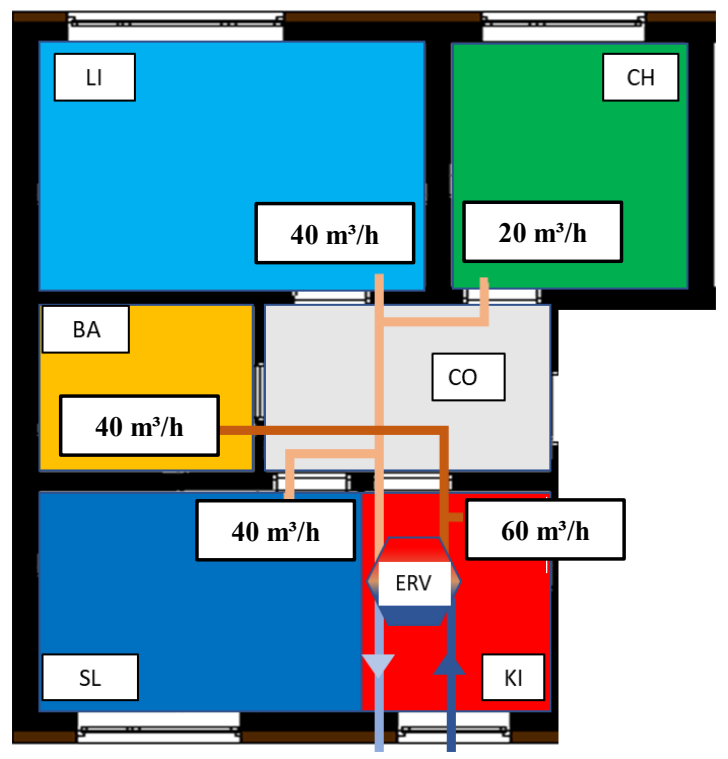

$$
\begin{array}{ll}
V_{\text {exh }}: 100 & V_{\text {sup: }}: 100 \\
\mathbf{m}^{3} / \mathbf{h} & \mathbf{m}^{3 / h}
\end{array}
$$

Fig. 5. Simplified scheme of the decentralized ventilation system with energy recovery (ERV) in the flat. A supply airflow rate of $100 \mathrm{~m}^{3} / \mathrm{h}$ is supplied to SL, CH and LI and is extracted from the BA and KI. The ERV unit is combined with the supply air and recirculation air HP (see Fig. 4)

\subsection{Indoor unit}

In the standard configuration of such a system, the indoor unit can be installed in the ceiling of the kitchen of the flat (see Fig. 3). The functional model of the indoor unit (tested in the laboratory of the University of Innsbruck) is shown in Fig. 6. The unit is compact and represents a good solution, primarily for the case of limited space for energy renovation. The main components of the indoor unit are the ERV unit and the condenser and desuperheater of the heat pump.

The fresh air - optionally pre-heated in a pre-heater for frost-protection - is heated in the ERV unit and afterwards in the condenser of the heat pump before it is distributed in the corridor to the supply air rooms (i.e. SL, CH and LI). The extracted air (from bathroom and kitchen) is cooled in the ERV unit and is then driven to the evaporator installed in the outdoor unit (Fig. 7). In Fig. 6 is also visible the circuit of the secondary air that is extracted from the corridor, heated in the desuperheater and recirculated to the corridor.

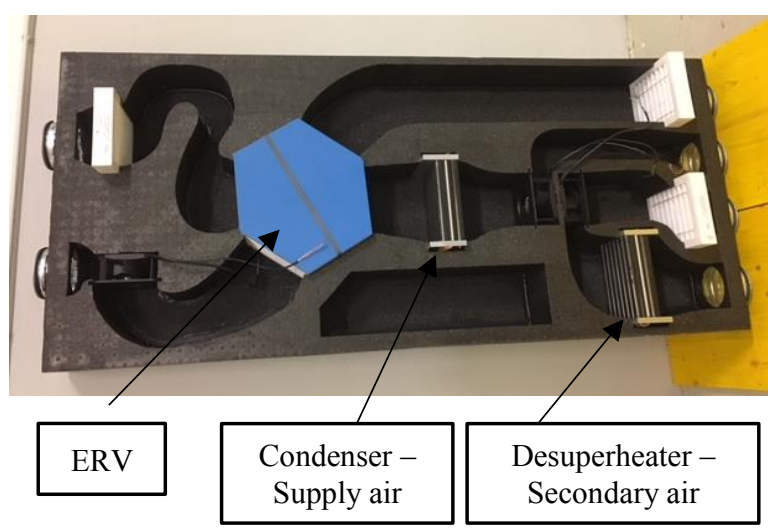

Fig. 6. Functional model of the indoor unit of the supply air heat pump with recirculation of secondary air and integrated silencers. The indoor unit can be installed in the ceiling of the kitchen (refrigerant split configuration) or as compact unit into the façade of the flat together with the outdoor unit.

\subsection{Outdoor unit}

Fig. 7 shows the outdoor unit of the proposed system installed into a prefabricated timber frame façade in the PASSYS test cell at the University of Innsbruck. As explained in section 3.1, this configuration represents one of the possible solutions in which the outdoor unit is completely integrated into a façade and the indoor unit is installed in the flat. The holes for the supply air, additional ambient air and exhaust air are visible on the façade. On the photo (Fig. 7, left) the inlet of the supply air and the outlet of the exhaust air, as well as the inlet of the additional ambient air that is used as additional source of the heat pump can be seen. The main components contained in the outdoor unit are the compressor, the evaporator and the expansion valve of the heat pump, whereas the condenser and the desuperheater are installed in the indoor unit. 

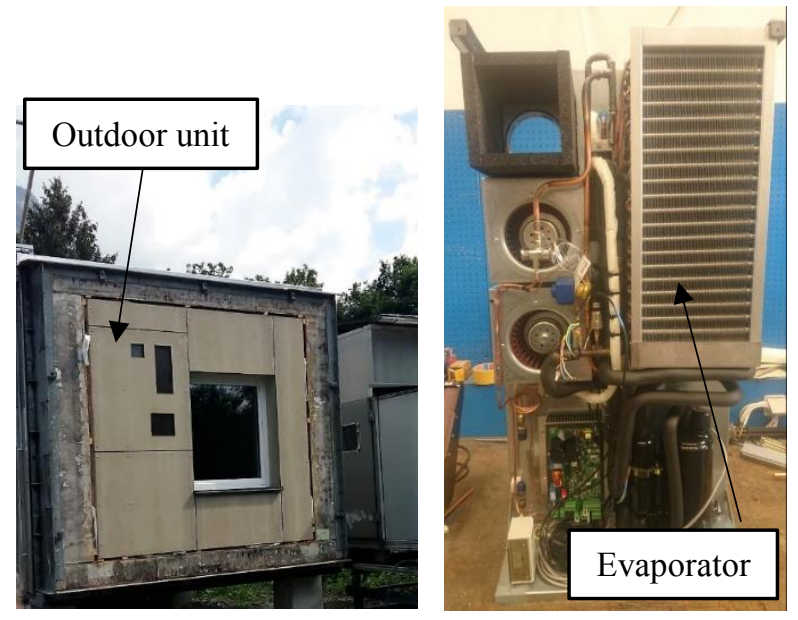

Fig. 7. Outside view of the outdoor unit integrated into the prefabricated timber frame façade in the PASSYS test cell (left) and outdoor unit in the laboratory at the University of Innsbruck (right).

\section{Building and System Simulation}

\subsection{Overview of simulation study}

An annual building and system simulation of the reference flat of the MFH located in Innsbruck (Austria) was performed in CARNOT, Matlab/Simulink in order to investigate the energy performance of the proposed system (i.e. supply air - exhaust air heat pump with recirculation of secondary air) and the thermal comfort and the IAQ in the flat. A set point temperature of $21^{\circ} \mathrm{C}$ for the heating system was assumed.

The flat of the first floor oriented to Northeast (see Fig. 1) was simulated, while the others flats (below, above and adjacent the flat simulated), basement, staircase and ambient are boundary conditions of the flat.

A balanced ERV unit (i.e. $V_{\text {sup }}=V_{\text {extr }}$ ) supplies $100 \mathrm{~m}^{3} / \mathrm{h}$ of fresh air to the sleeping room (SL), child room $(\mathrm{CH})$ and living room (LI) $\left(40 / 20 / 40 \mathrm{~m}^{3} / \mathrm{h}\right.$, respectively) and extracts air from the kitchen (KI) and bathroom (BA) $\left(60 / 40 \mathrm{~m}^{3} / \mathrm{h}\right.$, respectively). Sensible $\left(\eta_{\mathrm{T}}\right)$ and latent $\left(\eta_{\mathrm{w}}\right)$ effectiveness of 0.77 and 0.6 are assumed, respectively.

A secondary air flow rate of $100 \mathrm{~m}^{3} / \mathrm{h}$ were considered and an additional ambient air of $200 \mathrm{~m}^{3} / \mathrm{h}$ was used as source of the heat pump in addition to the exhaust air.

All the doors of the flat were considered closed, except the doors of kitchen and living room.

\subsection{Model of the ventilation and heating system in Carnot, Matlab/Simulink}

Fig. 8 shows a simplified block diagram of the heating system model created in CARNOT (Matlab/Simulink see section 2). The power of the heat pump is controlled with a temperature sensor installed in the corridor and, optionally, an additional temperature sensor is installed in the living room to avoid underheating in the supply air rooms.
This heating system with supply air and secondary air recirculation gives the possibility to heat the flat with two modes:

- If $\mathrm{T}_{\mathrm{LI}}<\mathrm{T}_{\mathrm{SP}}$, the supply air is used to heat the flat;

- If $T_{L I}>T_{S P}$, supply air and secondary air are used to deliver heating power

Where $T_{L I}$ and $T_{S P}$ represent the operative temperature of the living room and the set point temperature of the heating system, respectively.

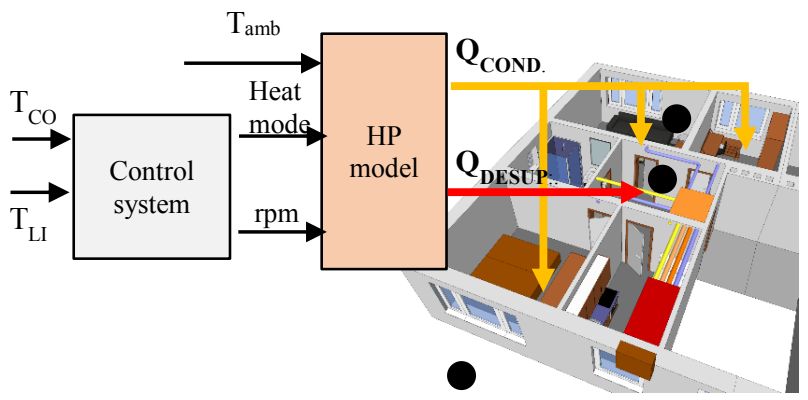

Fig. 8. Block diagram of the system implemented in CARNOT, Matlab/Simulink. The black points indicate the position of the temperature sensors considered (i.e. ambient, $\mathrm{CO}$ and LI). "Heat mode" indicates the mode with which the power is delivered to the flat: with supply (i.e. condenser is activated) or with supply and secondary air (i.e. condenser and desuperheater are activated) [7].

Two different sets of Performance Maps (PMs), derived from laboratory measurements, were implemented in CARNOT. Depending on the compressor speed (revolutions per minute, rpm), the ambient air temperature $\left(T_{a m b}\right)$ and "Heat mode" (i.e. with condenser or with condenser and desuperehater), total heating power and Coefficient of Performance (COP) of the heat pump are given. Fig. 9 reports the PM in case of supply air heating and

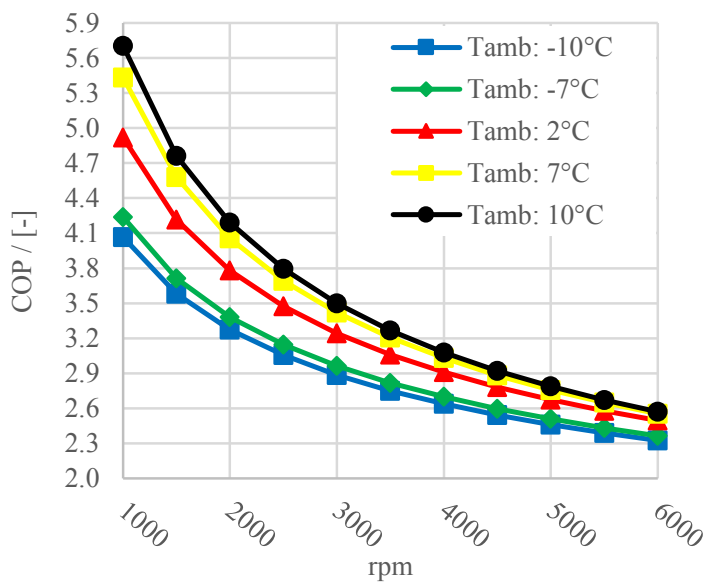

Fig. 10 in case of supply and secondary air heating. In the letter case, the heating power was equally split between the condenser $(50 \%)$ and the desuperheater $(50 \%)$. 

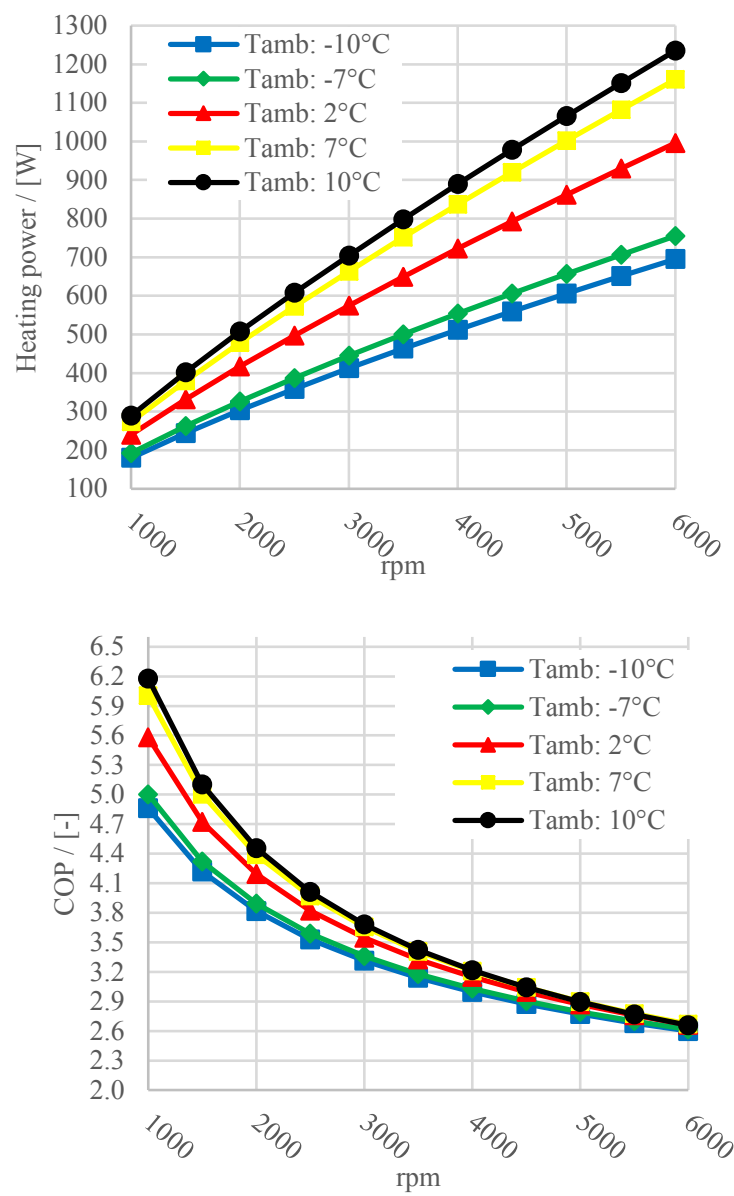

Fig. 9. Performance map of the power of the heat pump (top) and the COP (bottom) depending on the rpm of the compressor and the ambient air temperature - Heating with supply air

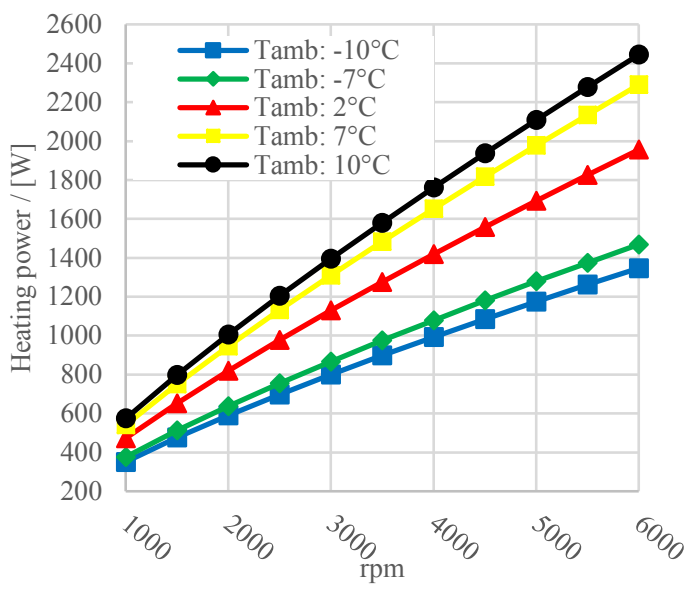

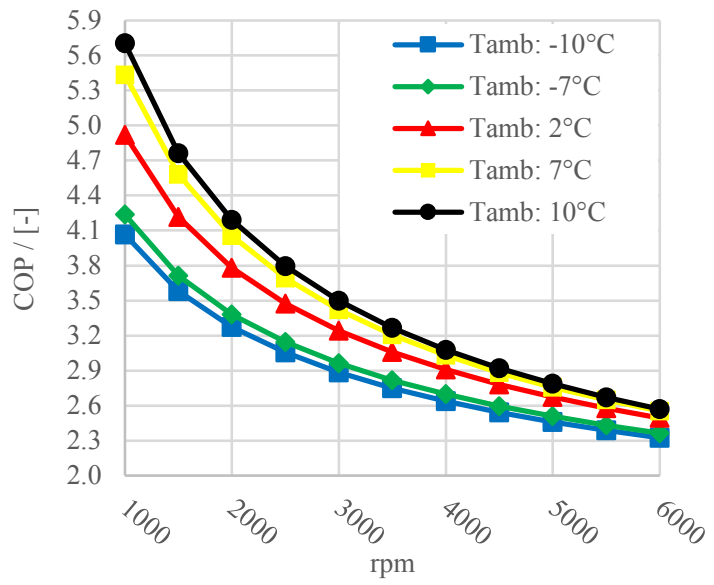

Fig. 10. Performance map of the power of the heat pump (top) and the COP (bottom) depending on the rpm of the compressor and the ambient air temperature - Heating with supply and secondary air

\subsection{KPIs}

Four Seasonal Performance Factors (SPFs) were defined according to the equations (1)-(4) in order to evaluate the energy performance of the components and of the system and to be able to compare it with a reference heating concept.

$$
\begin{aligned}
S P F_{H P} & =\frac{\left(Q_{\text {Condenser }}+Q_{\text {Desup }}\right)}{\left(W_{\text {el, } \text { Compresssor }}+W_{\text {el,Vsec }}+W_{\text {el,Vamb }}\right)} \\
S P F_{\text {sys }}= & \frac{\left(Q_{H P}+Q_{\text {Post-heater }}+Q_{\text {Radiator }}\right)}{\left(W_{\text {el,HP}}+W_{\text {el,Post-heater }}+W_{\text {el,Radiator }}\right)} \\
S P F_{E R V} & =\frac{\left(Q_{\text {Pre-heater }}+Q_{H X}\right)}{\left(W_{\text {el,Pre-heater }}+W_{\text {el,Fans }}\right)} \\
S P F_{\text {tot }}= & \frac{\llbracket\left(Q \rrbracket_{E R V}+Q_{\text {sys }}\right)}{\llbracket\left(W \rrbracket_{\text {el,ERV }}+W_{\text {el,sys }}\right)}
\end{aligned}
$$

where:

- $Q_{\text {Condenser }}$ and $Q_{\text {Desup }}$ represent the thermal energy delivered by the condenser and desuperheater, respectively;

- $W_{\text {el,Compresssor }}$ represents the electric consumption of the compressor;

- $W_{e l, V s e c}$ is the electric consumption of the secondary air fan;

- $W_{\text {el,Vamb }}$ is the electric consumption of the fan for the additional ambient air (electric power of fan for compressor cooling is included);

- $Q_{\text {Post-heater }}$ and $W_{\text {el,Post-heater }}$ represent the thermal energy and the electric consumption of the post-heater after the heat pump, respectively;

- $Q_{\text {Radiator }}$ and $W_{\text {el,Radiator }}$ represent the energy and electricity consumption of the electric radiator installed in the bathroom, respectively;

- $Q_{\text {Pre-heater }}$ and $W_{\text {el,Pre-heater }}$ represent the thermal energy and the electric consumption of the pre-heater installed before the ERV unit, respectively; 
- $Q_{H X}$ is the thermal energy exchanged in the ERV unit during the heating season.

The seasonal performance factor of the heat pump, $S P F_{H P}$, incudes the electricity consumption of the two additional fans for the secondary air (Specific Fan Power (SFP) of $0.093 \mathrm{Wh} / \mathrm{m}^{3}$ ) and for the additional ambient air $\left(\mathrm{SFP}=0.0565 \mathrm{Wh} / \mathrm{m}^{3}\right)$. The electric power consumption of the fans $W_{\text {el,Fans }}$ is considered in the definition of $S P F_{E R V}$ and indicates only the electricity consumption of the two fans for supply and extracted airflow rate (SFP = $0.4 \mathrm{Wh} / \mathrm{m}^{3}$ ). An additional consumption of $10 \mathrm{~W}$ was assumed for standby.

\section{Simulation results and discussion}

\subsection{Thermal comfort and IAQ}

Fig. 11 shows, for each room of the flat the simulated relative humidity vs. the operative temperature. During the winter time, all the rooms are in the "comfort" or "acceptable" region, while some overheating occurs during the summer. Active cooling would be possible with the proposed system but is not considered in this study. However, summer overeheating of the rooms is at least partially prevented by passive cooling, i.e. shading and opening of the windows (night cooling).

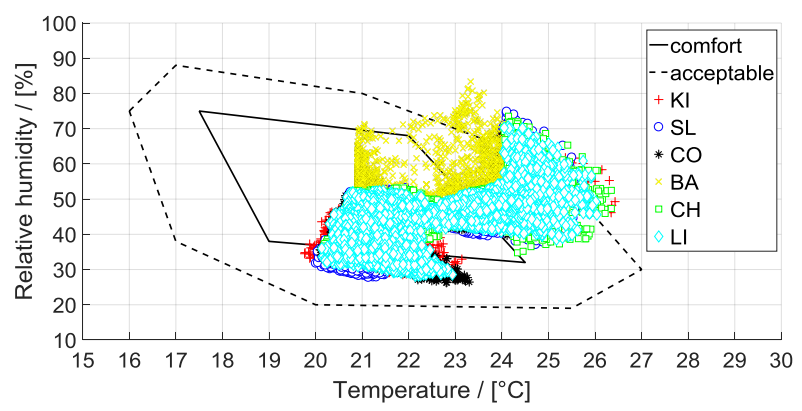

Fig. 11. Thermal comfort region and hourly average values of relative humidity vs. temperature for each room of the flat

As discussed in section 3.1, the investigated heating system is a supply air - exhaust air HP in combination with MVHR with an additional condenser (desuperheater) for secondary air heating. Fig. 12 shows the comparison between a conventional supply air heating system and the proposed systems with additional recirculation air with regard to the operative temperatures of the zones during the winter time. The well-known problem of overheating of supply air rooms (i.e. LI, CH and SL) in case of supply air heating can be avoided with the new system with recirculation, as an additional degree of freedom in the control is given by the possibility to split the heat flow to the condenser and the desuperheater. In both cases, an additional electric radiator installed in the bathroom I recommended for reasons of comfort. It keeps its temperature constant at $21^{\circ} \mathrm{C}$ in this study.

The $\mathrm{CO}_{2}$ concentration in the different rooms is shown in Fig. 13. The IAQ is good in all the rooms. The child room is characterised by the maximum values of $\mathrm{CO}_{2}$ detected
(1025 ppm). Because of the assumption of closed doors in $\mathrm{CH}$ and SL and open door in LI and KI (see section 4), $\mathrm{CO}_{2}$ concentration is slightly higher in $\mathrm{CH}$ and $\mathrm{SL}$ and levelled in LI.
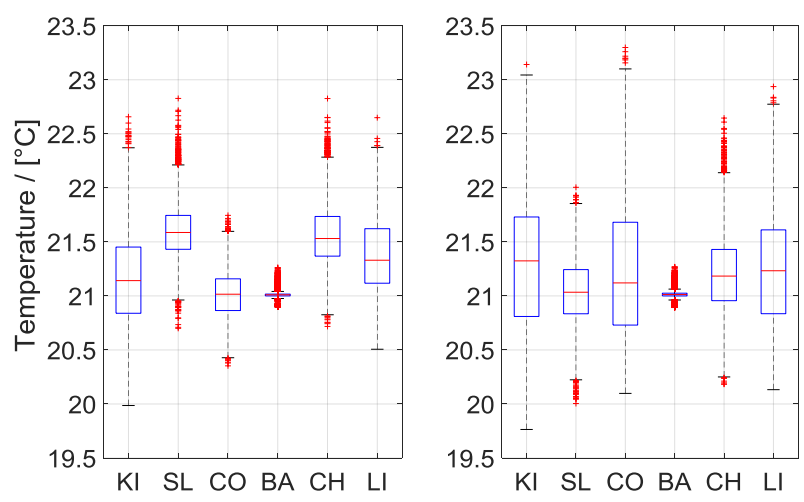

Fig. 12. Operative temperature (hourly average) for each room of the flat during the heating season in case a supply air - exhaust air HP (left) or a supply air - exhaust air HP with secondary air (right) is used to heat the flat

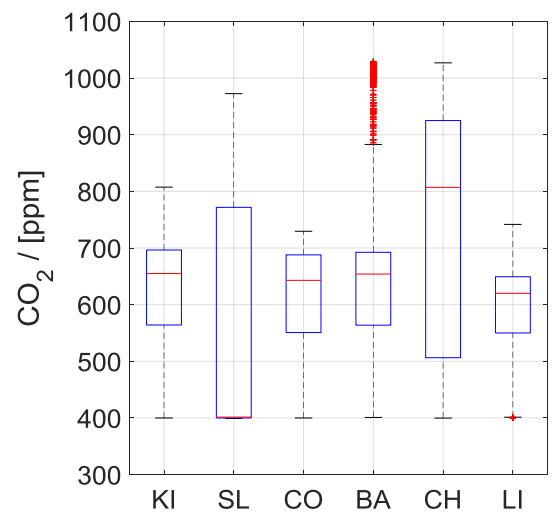

Fig. 13. Box plot of $\mathrm{CO}_{2}$ concentration (hourly average values) for each room of the flat $-\mathrm{CO}_{2}$ of ambient of $400 \mathrm{ppm}$ is considered

\subsection{Energy performances}

Fig. 14 and Table 1 show the comparison between the investigated system (i.e. supply air - exhaust air HP with secondary air) and the reference configuration without desuperheater in terms of energy performances (SPFs) and energy and electricity demand. Both systems have practically the same energy performances with a $\mathrm{SPF}_{\mathrm{HP}}$ of 2.4 and a $\mathrm{SPF}_{\text {tot }}$ of 3.2. Because of the relative high share of the direct heating (i.e. electric radiator installed in the bathroom), $\mathrm{SPF}_{\mathrm{sys}}$ is significantly lower compared to $\mathrm{SPF}_{\mathrm{HP}}$. The slightly higher temperature of the extracted air in case of secondary air system explains the higher $\mathrm{SPF}_{\text {ERV }}$ compared to the reference system. The energy performances of both systems is comparable, but the new system is able to ensure better thermal comfort in the flat (see Fig. 12). The slight overheating of the supply air rooms (i.e. SL, CH and LI) in case of the reference system explains the higher heating demand $\left(30.5 \mathrm{kWh} /\left(\mathrm{m}^{2} \mathrm{a}\right)\right)$ compared to the system in which secondary air is used $\left(28.3 \mathrm{kWh} /\left(\mathrm{m}^{2} \mathrm{a}\right)\right)$ (see Table 1$)$. 


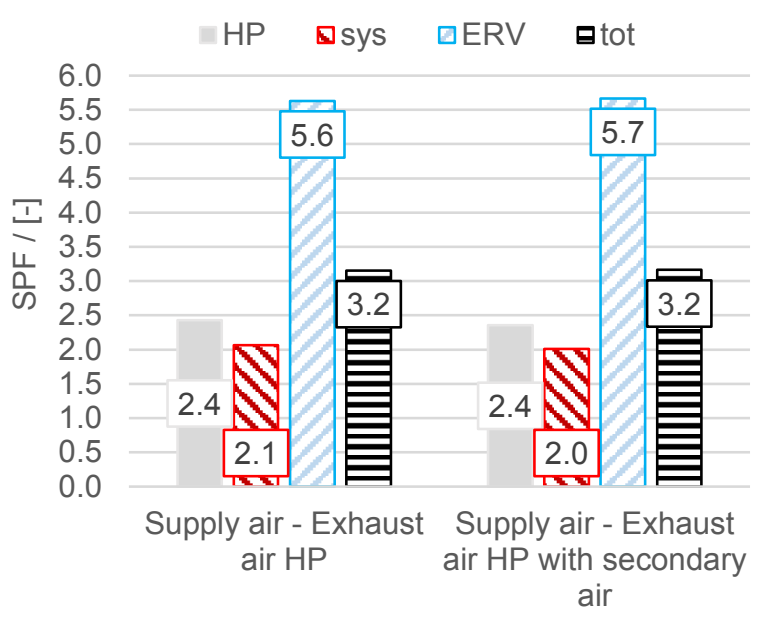

Fig. 14. Annual SPFs (based on the equations (1) - (4), see section 4.3) for the proposed system (right) and comparison with the standard heating concept without desuperheater (left)

Table 1. Heating demand (HD), maximum hourly heating load (HL) and electricity demand (ED) for the proposed and the standard system. The electric power of the fan for compressor cooling (for both systems) and for secondary air (only for system with secondary air) are taken into acount

\begin{tabular}{|c|c|c|}
\hline & $\begin{array}{c}\text { Supply air - } \\
\text { Exhaust air HP }\end{array}$ & $\begin{array}{c}\text { Supply air - } \\
\text { Exhaust air HP } \\
\text { with secondary } \\
\text { air }\end{array}$ \\
\hline $\begin{array}{c}\mathrm{HD} \\
{\left[\mathrm{kWh} /\left(\mathrm{m}^{2} \mathrm{a}\right)\right]}\end{array}$ & 30.5 & 28.3 \\
\hline $\begin{array}{c}\mathrm{HL} \\
{\left[\mathrm{W} / \mathrm{m}^{2}\right]}\end{array}$ & 17.3 & 22.7 \\
\hline $\begin{array}{c}\mathrm{ED} \\
{\left[\mathrm{kWh} /\left(\mathrm{m}^{2} \mathrm{a}\right)\right]}\end{array}$ & 14.8 & 14.1 \\
\hline
\end{tabular}

\subsection{Detailed simulation results}

Fig. 15 and Fig. 16 show the heating power and the electric power of the investigated heating system, respectively. The heating season lasts 8 months (1 October - 1 June) and $13 \%$ of the total heating energy is delivered through direct heating (i.e. heating of BA through electric radiator). Almost $50 \%$ of the total electricity consumption of the HVAC system is due to the compressor (see Fig. 16), but also a relevant part is due to the ventilation system (32\%) that works for the entire year (a constant supply airflow rate $\left(100 \mathrm{~m}^{3} / \mathrm{h}\right)$ throughout the year was assumed).

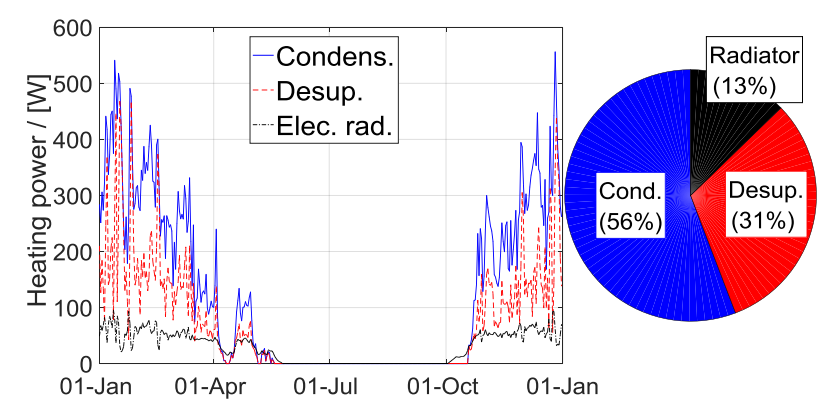

Fig. 15. Daily average values of the heating power (left) and pie chart of the annual heating demand of the flat (right) - Heating demand of $2005 \mathrm{kWh} / \mathrm{a}\left(28.3 \mathrm{kWh} /\left(\mathrm{m}^{2} \mathrm{a}\right)\right)$ [7]

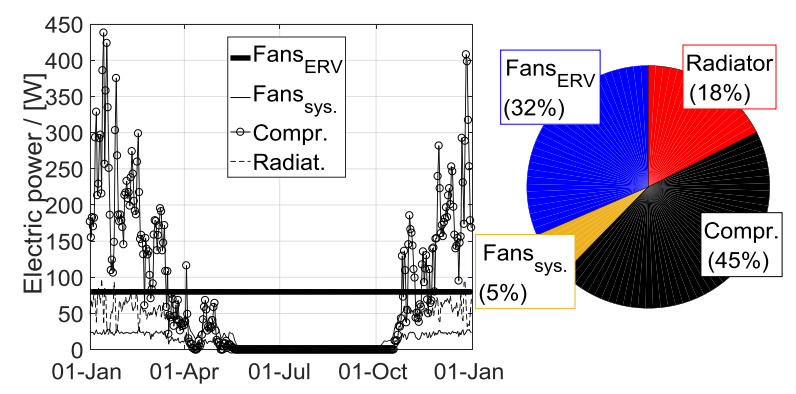

Fig. 16. Electric power (daily average values, left) and pie chart of the electricity demand of the HVAC system (right). "Fanserv." indicates the two fans (i.e. supply and extract air) of the ventilation system, while "Fans sys." represents the fans of the heating system (i.e. for secondary air, additional ambient air and compressor cooling). An annual electricity consumption of $1456.4 \mathrm{kWh} / \mathrm{a}$ was calculated. [7]

\section{Conclusions}

In the framework of the Austrian project SaLüH!, a new heating and ventilation concept based on a façade integrated supply air-exhaust air heat pump with secondary air recirculation was developed, tested in the laboratory and investigated by means of a simulation study in CARNOT, Matlab/Simulink. The proposed system is suggested as a solution for non-disruptive decentral renovation of flats in multi-family houses.

The system is, because of the additional degree of freedom for control by using secondary air recirculation heating able to ensure better thermal comfort compared to the reference supply air heating system in which heating is coupled to the hygienic air flow rate. Good IAQ with a maximum value of $\mathrm{CO}_{2}$ of $1025 \mathrm{ppm}$ is obtained in both systems.

Comparable energy performances were found for both systems (i.e. with or without desuperheater) with a $\mathrm{SPF}_{\mathrm{sys}}$ of 2.0 and a SPF tot (including ERV) of 3.2. The system performance could be further improved by reducing the share of direct electric heating (in the bathroom). However, as the system is supposed to be applied in flats with very low heating demand a SPF of 2 is acceptable. It has to be considered that such a system has to be compact and cost-effective and it competes direct electric heating or maybe mini-split heat pumps. 
The system was tested in the PASSYS laboratory test environment in real scale also for sound emissions, where future work will be focusing on. In further future work, the control should be further optimized with respect to avoid the slight underheating in the sleeping and child room.

Remark: Within the project SaLüH!, in addition, a compact air to water DHW heat pump was developed, see [3].

\section{References}

[1] Ochs F., Dermentzis G., Siegele D., Façade Integrated MVHR and Heat Pump, in: 12th Conference on Advanced Building Skins 2-3 October 2017, Bern, Switzerland, 2017.

[2] Calabrese T., Ochs F., Siegele D., Dermentzis G., 2018. Potential of covering electricity needs of a flat of a MFH with decentral compact heat pumps with PV - Simulation study for different DHW profiles and PV field sizes, in: EUROSUN 2018 10-13 September 2018, Rapperswil, Switzerland, 2018.

[3] https://www.uibk.ac.at/bauphysik/forschung/pro jects/saluh/index.html.de

[4] Fabian Ochs, Martin Hauer, Michele Bianchi Janetti, Siegele Dietmar, Energy Performance of Membrane Energy Recovery Ventilation in Combination with an Exhaust Air Heat Pump, IBPSA 2017, USA

[5] Rojas Kopeinig, 2015. Lüften und Heizen in Passivhäusern in Österreich Variantenvergleich auf Basis von Behaglichkeit und Nachhaltigkeit, Schriftenreihe 36/2015, G. Rojas, M. Spörk-Dür, D. Venus, A. Greml, L. Krissmer, R. Pfluger, Herausgeber: bmvit

[6] Calabrese T., Ochs F., Siegele D., Dermentzis G., 2018. D3.2 Bericht zur Analyse des Komforts und der Luftqualität, Austrian project „SaLüH!“ (Sanierung von MFH mit kleinen Wohnungen - Kostengünstige technische Lösungsansätze für Lüftung, Heizung und Warmwasser)

[7] Calabrese T., Ochs F., Siegele D., Dermentzis G., 2018. D3.4 Bericht zu Simulationstools und Ergebnissen, Austrian project „SaLüH!“ (Sanierung von MFH mit kleinen Wohnungen Kostengünstige technische Lösungsansätze für Lüftung, Heizung und Warmwasser)

This work is part of the Austrian research project SaLüH! Renovation of multi-family houses with small apartments, lowcost technical solutions for ventilation, heating \& hot water (2015-2018); Förderprogramm Stadt der Zukunft, FFG, Project number: 850085 . 